\title{
Fluorescent chromosome banding patterns of several species in the Cupressaceae sensu stricto
}

\author{
Masahiro Hizume $^{1}$ and Michiyo Fujiwara \\ Faculty of Education, Ehime University, Matsuyama 790-8577, Japan \\ ${ }^{1}$ Author for correspondence: (hizume@ed.ehime-u.ac.jp) \\ Received March 18, 2016; accepted March 23, 2016
}

\begin{abstract}
Thirteen species among eight genera in Cupressaceae sensu stricto were studied on somatic chromosome bandings by sequential fluorescent staining with chromomycin $\mathrm{A}_{3}$ (CMA) and 4',6-diamidino-2-phenylindole (DAPI). All species were diploid $(2 n=22)$ and had symmetric and homogeneous karyotype. Two CMA-bands appeared on chromosome complements of Callitris rhomboidea, Chamaecyparis obtsusa, Ch. pisifera, Cupressus lusitanica, Juniperus rigida, Microbiota decussate, Platycladus orientalis, Thuja plicata, and T. standishii. Actinostrobus pyramidalis, Ch. lawsoniana, and Cup. duclouxiana had four CMA-bands. Cupressus macrocarpa had six CMA-bands. CMA-bands appeared at interstitial region of chromosomes and their location was coincided with the site of secondary constrictions in all species. Microbiota decussate had unique weak CMA-bands at the proximal regions of 10 chromosomes in addition to two bright CMA-bands. After DAPI-banding whole chromosome arms of each species fluoresced excepting for region of CMA-bands. Cupressus duclouxiana had weak DAPI-bands on few chromosomes.
\end{abstract}

KEYWORDS: Chromomycin $\mathrm{A}_{3}$, Cupressaceae, DAPI, Fluorescent banding, Karyotype

The Cupressaceae sensu stricto and the Taxodiaceae have same basic chromosome number of $x=11$. Most species of the two families are diploid, while a few genera of these two families such as Sequoia sempervirens $(2 n=66)$ and Fitzroya cupressoides $(2 n=44)$, varieties or cultivars in Juniperus chinensis $(2 n=33,44)$ and, triploid and tetraploid plants in certain species (Ahuja 2005) consist of polyploid species. Recent molecular phylogenetic studies revealed evidently that the Cupressaceae sensu stricto and Taxodiaceae form a clade and should be put together into the family Cupressaceae sensu lato (Gadek et al. 2000; Kusumi et al. 2000; Yang et al. 2012).

Species of the Taxodiaceae were studied extensively with respect to karyotype and fluorescent banding pattern (Hizume et al. 1988a; Hizume 1989; Toda 1996) and in a few species such as Cryptomeria japonica (Hizume 1996; Hizume et al. 1998b), Cunninghamia lanceolata (Hizume 1996), Sequoiadendron gaiganteum (Nakamura and Fukui 1997) were analysed by in situ hybridization (ISH). In Cupressaceae sensu stricto, karyotypes were reported in species of almost half the number of genera such as Chamaecyparis (Kuroki 1969; Li et al.1996a; Maeda and Miyajima 1977), Callitris (Mehra and Khoshoo 1956; Hair 1968; Li et al. 1994), Juniperus (Mehra and Khoshoo 1956; Nagano et al. 2000), Cupressus (Mehra and Khoshoo 1956; Hunziker 1961; Li and Fu 1996; Thomas and Goggans 1972), Thuja (Mehra and Khoshoo 1956; Li et al. 1996b), Libocedrus (Hunziker 1961; Schalbaum and Tsuchiya 1975) and the genus containing a few species such as Fitzroya (Hair 1968), Platycladus (Mehra and Khoshoo 1956; Li and Hsu 1984), Fokienia (Li and Hsu 1984.), Actinostrobus (Mehra and Khoshoo 1956; Hair 1968), Tetraclinis (Mehra and Khoshoo 1956; Hair 1968), Pilgerdendron (De Azkue 1982) and Widdringtonia (Mehra and Khoshoo 1956). The karyotype reported previously supplied no information contributing to phylogenetic relationship among the species and the genera in Cupressaceae sensu stricto. Modern techniques of karyotype analysis were adapted to a few species of the Cupressaceae sensu stricto Fluorescent banding and silver staining were adapted to chromosomes of Cupressus sempervirens (Hizume 2014). This study showed clear CMA-bands on secondary constriction and interstitial and proximal DAPI-bands useful for chromosome identifycation. Fluorescence in situ hybridization (FISH) using rDNA probe in J. chinensis and J. lutchuensis (Nagano et al. 2007) indicating $18 \mathrm{~S}$ rDNA localized at the secondary constriction and 5S rDNA did at proximal region the shortest chromosome. Recently Vallès et al. (2015) reported FISH of rDNA in four Juniperus species and discussed relationships between FISH signal of rDNA and CMA-band.

\section{Materials and Methods}

Seeds or plantlets were collected and obtained from botanical gardens or natural forests (Table 1).

Root tips were collected from plantlets in pots or germinating seed on filter paper in petri dishes treated with $2 \mathrm{mM} 8$-hydroxiquinolin at $20^{\circ} \mathrm{C}$ for $8-10 \mathrm{hrs}$. The root tips were fixed in ethanol-acetic acid (3:1) and stored in a deep freezer until observation. The root tips were rinsed with distilled water for $5 \mathrm{~min}$ and transferred in $45 \%$ acetic acid for $5 \mathrm{~min}$, then treated in $45 \%$ acetic acid at $60^{\circ} \mathrm{C}$ for $10 \mathrm{~min}$. On a glass slide meristematic tissue was dissected and squashed in $45 \%$ acetic acid. The slides were put on dry ice and after frozen were removed cover slips, air-dried overnight. Procedures of fluorescent banding technique were referred to Kondo and Hizume (1982) and Hizume (2014). The slides were soaked in McIlvaine buffer $\mathrm{pH} 7.0$ and treated $1 \mathrm{mg} / \mathrm{ml}$ distamycin 
Table 1. Origin and locality, chromosome number and summary of fluorescent banding in the species of the Cupressaceae sensu stricto examined.

\begin{tabular}{|c|c|c|c|c|}
\hline Species & $\begin{array}{l}\text { Chromoso } \\
\text { me number } \\
(2 n)\end{array}$ & $\begin{array}{l}\text { Number of } \\
\text { CMA-bands }\end{array}$ & $\begin{array}{l}\text { Presence of } \\
\text { DAPI-bands }\end{array}$ & Origin and locality \\
\hline $\begin{array}{l}\text { Actinostrobus pyramidalis } \\
\text { Miquel }\end{array}$ & 22 & 4 & - & $\begin{array}{l}\text { Wollongong Botanical Garden, NSW, } \\
\text { Australia }\end{array}$ \\
\hline $\begin{array}{l}\text { Callitris rhomboidea Brown } \\
\text { ex Rich. et Rich. }\end{array}$ & 22 & 2 & - & $\begin{array}{l}\text { Wollongong Botanical Garden, NSW, } \\
\text { Australia }\end{array}$ \\
\hline $\begin{array}{l}\text { Chamaecyparis lawsoniana } \\
\text { (A. Murray) Parl. }\end{array}$ & 22 & 4 & - & $\begin{array}{l}\text { Botanical Garden, Agricaltural } \\
\text { University, Wageningen, Netherland }\end{array}$ \\
\hline $\begin{array}{l}\text { Chamaecyparis obtusa Sieb. } \\
\text { \& Zucc. }\end{array}$ & 22 & 2 & - & Matsuyama, Ehime, Japan \\
\hline $\begin{array}{l}\text { Chamaecyparis pisifera } \\
\text { (Sieb. \& Zucc.) Endl. }\end{array}$ & 22 & 2 & - & $\begin{array}{l}\text { Institute of Forest Product and Forestry, } \\
\text { Tsukuba, Ibaraki, Japan }\end{array}$ \\
\hline $\begin{array}{l}\text { Cupressus duclouxiana } \\
\text { Hickel }\end{array}$ & 22 & 4 & + & $\begin{array}{l}\text { Institute of Forest Product and Forestry, } \\
\text { Tsukuba, Ibaraki, Japan }\end{array}$ \\
\hline Cupressus lusitanica Miller & 22 & 2 & - & $\begin{array}{l}\text { Botanical Garden, Agricaltural } \\
\text { University, Wageningen, Netherland }\end{array}$ \\
\hline $\begin{array}{l}\text { Cupressus macrocarpa } \\
\text { Hartweg ex Gordon }\end{array}$ & 22 & 6 & - & $\begin{array}{l}\text { Botanical Garden, Agricaltural } \\
\text { University, Wageningen, Netherland }\end{array}$ \\
\hline $\begin{array}{l}\text { Juniperus rigida Sieb. \& } \\
\text { Zucc. }\end{array}$ & 22 & 2 & - & Mt. Tagmi, Iyo, Ehime, Japan \\
\hline Microbiota decussata Kom. & 22 & $2+10^{*}$ & - & $\begin{array}{l}\text { Aritaki Aboretum, kosigaya, Saitama, } \\
\text { Japan }\end{array}$ \\
\hline $\begin{array}{l}\text { Platycladus orientalis } \\
\text { (Linnaeus) Franco }\end{array}$ & 22 & 2 & - & Cultivated in Ehime university \\
\hline $\begin{array}{l}\text { Thuja plicata Donn ex D. } \\
\text { Don }\end{array}$ & 22 & 2 & - & $\begin{array}{l}\text { Montana, Idaho, Washington, Oregon } \\
\text { and California }\end{array}$ \\
\hline $\begin{array}{l}\text { Thuja standishii (Gordon) } \\
\text { Carrière }\end{array}$ & 22 & 2 & - & $\begin{array}{l}\text { KamigamoForest Station, Kyoto } \\
\text { University,Kyoto, Japan }\end{array}$ \\
\hline
\end{tabular}

* Number of weak proximal CMA-bands.

A for $10 \mathrm{~min}$ and rinsed with the buffer containing $5 \mathrm{mM}$ $\mathrm{MgCl}_{2}$ (Mg buffer), stained with $0.1 \mathrm{mg} / \mathrm{ml} \mathrm{CMA}$ for 15min. After rinse with the Mg buffer the slide mounted in glycerol and stored in a refrigerator overnight. CMA-stained preparation was observed CMA-band pattern under epi-fluorescence microscope using blue filter cassette. After observation slide was soaked in distilled water until coverslips dropped off. Preparation was immersed into the fixative for $30 \mathrm{~min}$, washed with DW and then soaked in the buffer. Then preparation was treated with $0.1 \mathrm{mg} / \mathrm{ml}$ actinomycin $\mathrm{D}$ for $10 \mathrm{~min}$, rinsed with the buffer for $5 \mathrm{~min}$ and stained in $0.1 \mu \mathrm{g} / \mathrm{ml}$ DAPI for $5 \mathrm{~min}$. Excess DAPI was removed by soak in the buffer and the preparation was mounted with mixture of the buffer and glycerol (1:1). DPAI-banded chromosomes were observed after DAPI-staining by fluorescent microscope with UV filter cassette. Photographs of banded chromosomes were recorded on film (Kodak T-max).

\section{Results and Discussion}

In two species of subfamily Callitroideae and 11 species of subfamily Cupressoideae examined, somatic chromosomes were observed $2 n=22$ and did not showed polyploidy or B-chromosomes (Figs. 1-7). Karyotype of Microbiota decussate was observed first time. The conventional karyotypes of other 12 species were similar to those of the previous studies. 

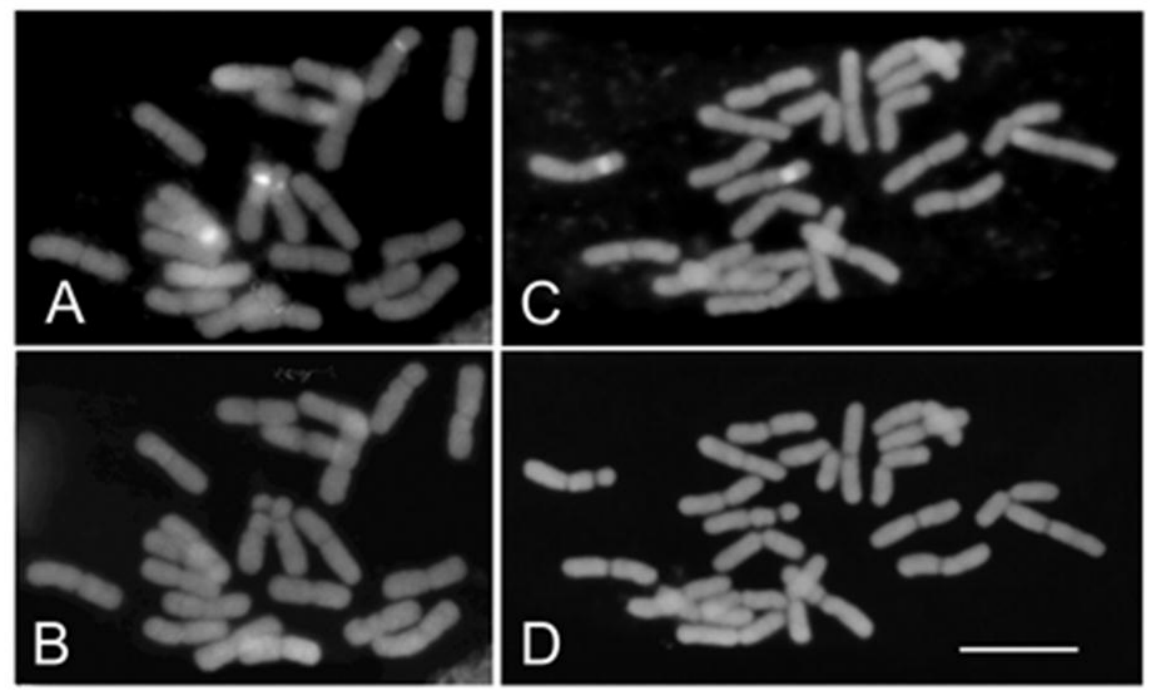

Fig. 1. Fluorescent banded chromosomes in Actinostrobus pyramidalis (A, B) and Callitris rhomboidea (C, D). A and $\mathrm{C}$ were stained with CMA. B and D were stained with DAPI. Bar=10 $\mu \mathrm{m}$
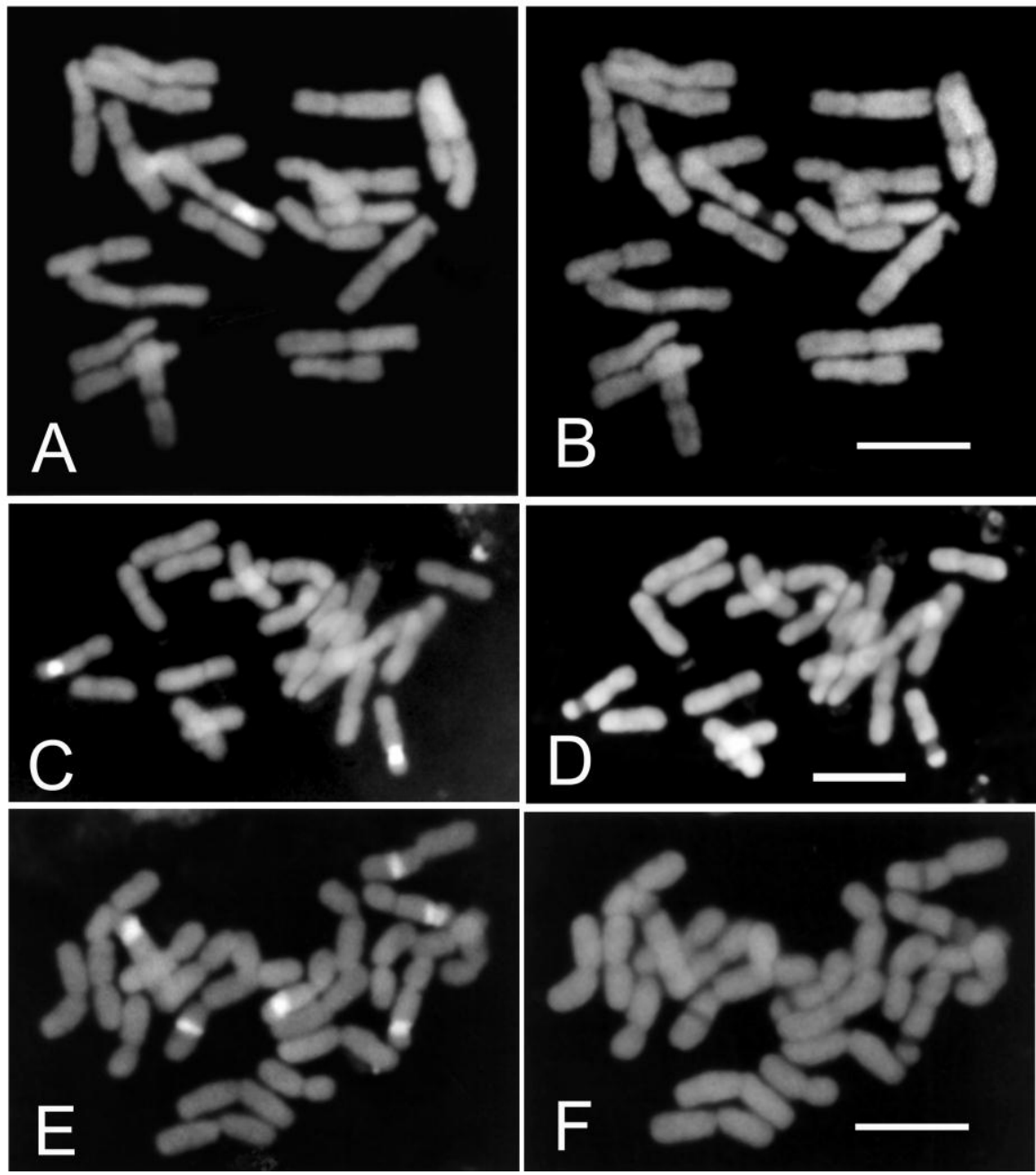

Fig. 2. Fluorescent banded chromosomes in three species of Chamaecyparis. A, B: Ch. obtsusa, C, D: Ch. pisifera and E, F:Ch. losoniana. A, C, E were stained with CMA and B, D, F were stained DAPI. Bar=10 $\mu \mathrm{m}$. 
Actinostrobus pyramidalis had the karyotype composed of 22 metacentric chromosomes and their karyotype is similar to previous reports by Mehra and Khoshoo (1956) and Hair (1968). The CMA -bands appeared four medium-sized metacentric chromosomes at the interstitial region of one arm (Fig. 1A). After DAPI-staining no bright DAPI-band appeared and regions of the CMA-band were DAPI -negative (Fig. 1B). Number of secondary constrictions was different from previous number of two (Mehra and Khoshoo 1956). Callitris rhomboidea showed two CMA-bands at the interstitial regions of two metacentric chromosomes (Fig. 1C) and the region of CMA-band was DAPI-negative (Fig. 1D).
Hiar (1968) reported karyotypes in five species of subfamily Callitroideae including $A$. pyramidali and $\mathrm{Ca}$. preissii and that these species had four secondary constrictions. Other ten species of Callitllis had two secondary constrictions (Mehra and Khoshoo 1956; Hair 1968).

Three species of Chamaecyparis, Ch. obtsusa, Ch. pisifera and Ch. lawsoniana were stained with CMA and DAPI (Fig. 2). CMA-bands appeared two in chromosome complements of Ch. obtsusa (Fig. 2A) and Ch. pisifera (Fig 2C), and four in Ch. lawsoniana (Fig 2E). Karyotypes of Chamecyparis species were reported previously (Kuroki 1969; Sasaki 1976; Maeda and Miyajima 1977;
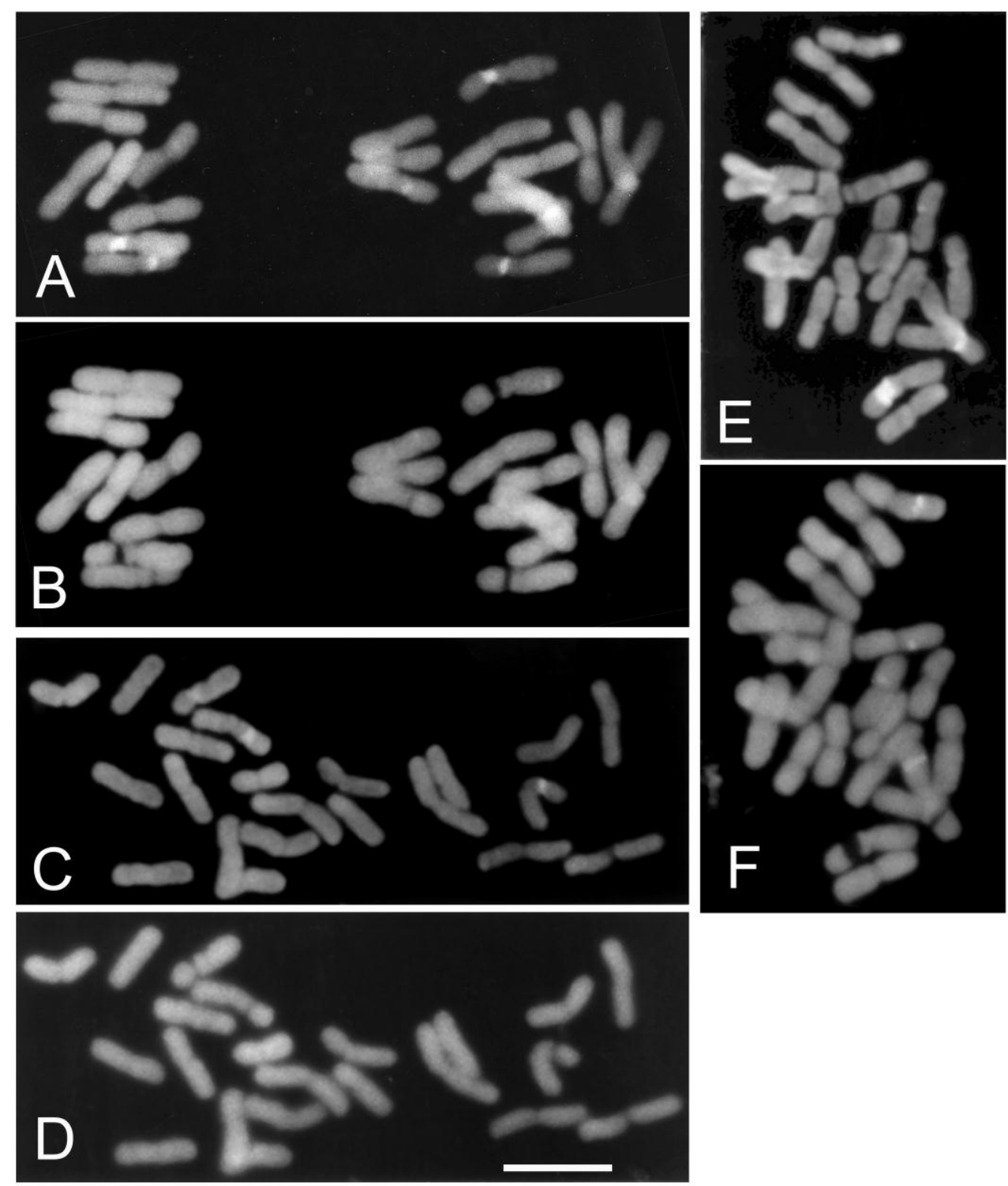

Fig. 3. Fluorescent banded chromosomes in three species of Cupressus. A and B. Cup. macrocarpa. C and D. Cup. lusitanica. E and F. Cup. duclouxiana. A, C and E were stained with CMA while B, D and F were stained DAPI. Bar $=10 \mu \mathrm{m}$. 
Ohguro and Okamura 1987) and are similar to this observation. After DAPI-staining chromosome arms fluoresced homogenously excepting for dark region corresponding to the CMA-band in all species (Fig. 2B, D, F). Kuroki (1969) and Ohguro and Okamura (1987) had recognized difference of location of secondary constrictions between Ch. obtsusa and Ch. pisifera. Our result $\mathrm{s}$ of CMA-banding supported this difference in position of the secondary constriction between these two species.

Fluorescent banded chromosomes were observed in three species of Cupressus. Cupressus macrocarpa had six CMA-bands (Fig. 3A), Cup. lusitanica had two (Fig. 3C) and Cup. duclouxiana had four composing two large and two small ones (Fig. 3E). Number of CMA-bands or secondary constrictions varied two to six among species and/or plants. After DAPI-staining Cup. macrocarpa (Fig. 3B) and Cup. lusitanica (Fig. 3D) homogeneous fluoresced excepting negative DAPI-band but only Cup. duclouxiana showed four DAPI-bands at the interstitial and near proximal region of chromosomes (Fig. 3F) like observed in Cup. sempervirens (Hizume 2014). In previous reports Cup. macrocarpa had two secondary constrictions (Camara and Jesus 1946) and Cup. lusitanica var. lusitanica have four secondary constrictions and ver. benthami had two secondary constrictions (Hunziker 1961). Chromosomes of Cup. sempervirens were investigated recently by fluorescent banding method using CMA and DAPI (Hizume 2014). Six CMA-bands and many interstitial DAPI-bands were observed in the karyotype of Cup. sempervirens. The fluorescent banding pattern of chromosomes permits to identify each homologous chromosome. Cupressus is relative large genus containing 16 species and nine varieties (Farjon 2001, 2005). The relationships among species will be revealed by fluorescent banding analysis especially with DAPI adapting to most species and comparative analysis between pattern of fluorescent bands and molecular phylogenetic analysis are desired. In molecular phylogenetic studies in Cupressaceae, Cupressus species were separated into two clades corresponding to distribution in New World and Old World (Little 2006). The DAPI-bands were observed in Cup. sempervirens and Cup. duclouxiana belonging to group of Old World. This diversification in Cupressus species might relate to presence of DNA sequence appeared as DAPI-band in genome. To clearly this speculation Cupressus species should be analyzed more on DAPI-band pattern of
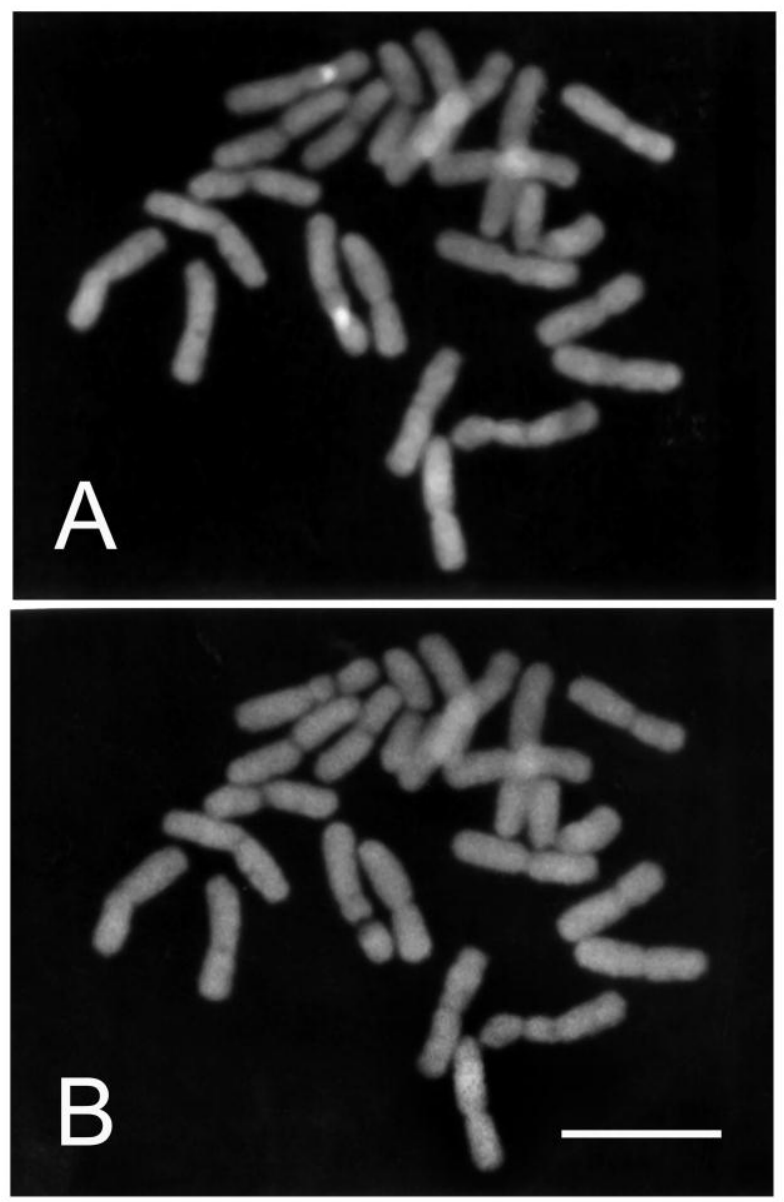

Fig. 4. Fluorescent banded chromosomes in Juniperus rigida. A was stained with CMA while B was stained with DAPI. Bar $=10 \mu \mathrm{m}$. 
chromosomes in more species.

Karyotype of $J$. rigida (Fig. 4) was similar to that reported by Kuroki (1969). Two CMA-bands appeared at interstitial region of two chromosomes and this region was DAPI-negative or secondary constrictions. Kuroki (1969) reported that two chromosomes had secondary constrictions and correspondence our CMA-bands observed. In the Cupressaceae sensu stricto FISH using 5S rDNA and $18 \mathrm{~S}$ rDNA probes were firstly applied to chromosomes of J. chinensis var. sargentii, J. chinensis var. procumbens $(2 n=44)$ and J. lutchuensis (Nagano et al. 2007). FISH signals of $18 \mathrm{~S}$ rDNA were localized at the interstitial secondary constriction in Mediterranean species of Juniperus (Vallès et al. 2015). This indicates that in Juniperus CMA-band at secondary constriction contains tandem repeat of $18 \mathrm{~S}$ rDNA as observed in many other plant species.

Microbiota decussate was reported firstly its chromosome number and karyotype in this study. The chromosomes of the 1st pair were metacentric with notably length and other chromosomes were also metacentric with gradual length variation (Fig. 5). The large and CMA-bands appeared at interstitial regions of two metacentric chromosomes (Fig. 5A). Weak
CMA-bands at proximal regions of one arms of 10 chromosomes and two chromosomes had weak CMA-bands at both proximal region. Proximal appearance of one arm of fluorescent band was only in this species among 13 species examined here. Fluorescent band locating at proximal region of one arm was observed also in Larix species but the bands of Larix were DAPI-bands (Hizume et al. 1988c). The first observation of proximal CMA-bands in fluorescent banding reports is in coniferous species. After DAPI-staining region of bright CMA-bands were DAPI-negative or secondary constrictions (Fig. 5B). The weak CMA-banded regions were not DAPI-negative.

Platycladus orientalis (Fig. 6) showed homogeneous karyotype with gradual length variation similar to that reported by Mehra and Khoshoo (1956), Kuroki (1969) and $\mathrm{Li}$ and Hsu (1984). Two CMA-bands appeared at interstitial region of two metacentric chromosomes (Fig. 6A) and these regions were DAPI-negative secondary constrictions (Fig. 6B). Kuroki (1969) reported two secondary constrictions and, Mehra and Khoshoo (1956) and Li. and Hsu (1984) did four secondary constrictions of two chromosome pairs distinguish each other by their position on chromosome arm. Our observation supports
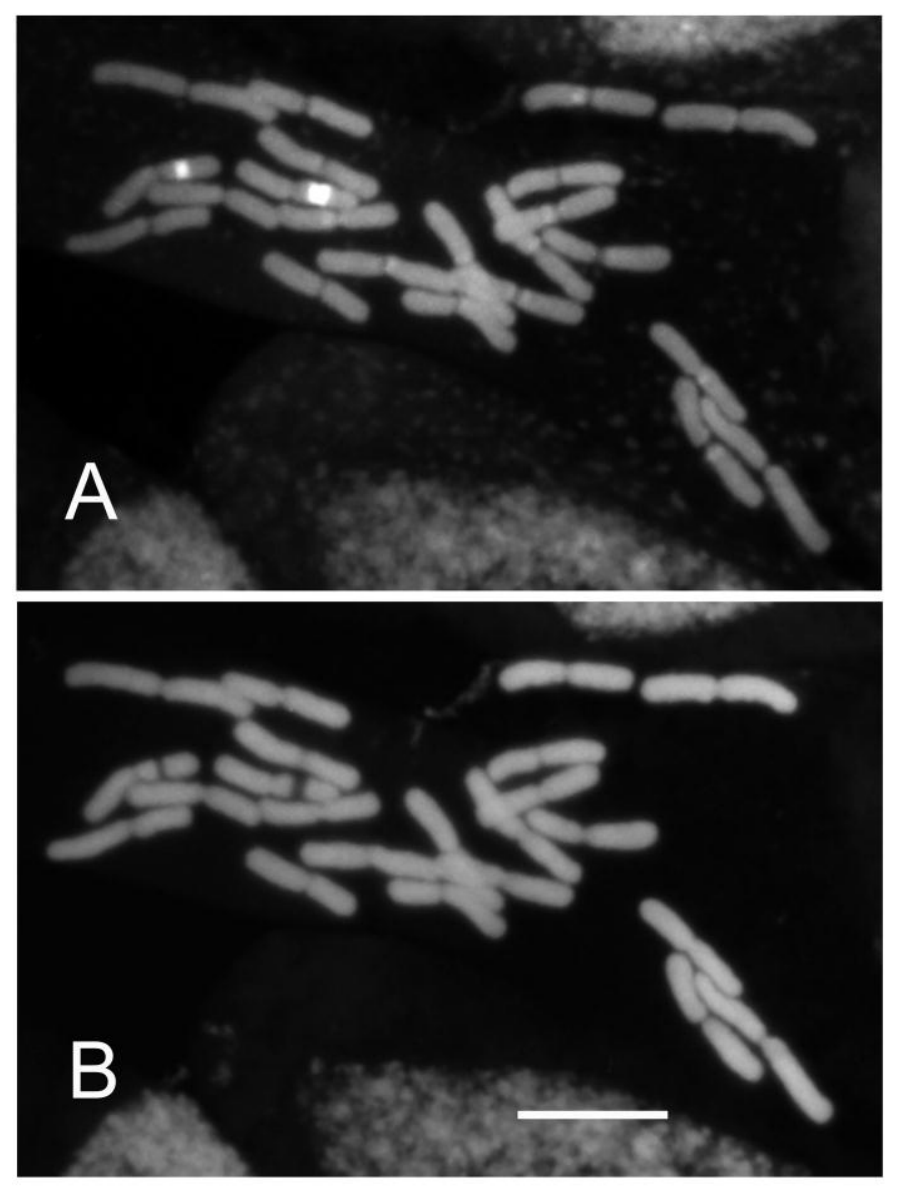

Fig. 5. Fluorescent banded chromosomes in Microbiota decussata. A was stained with CMA while B was stained with DAPI. Bar $=10 \mu \mathrm{m}$. 

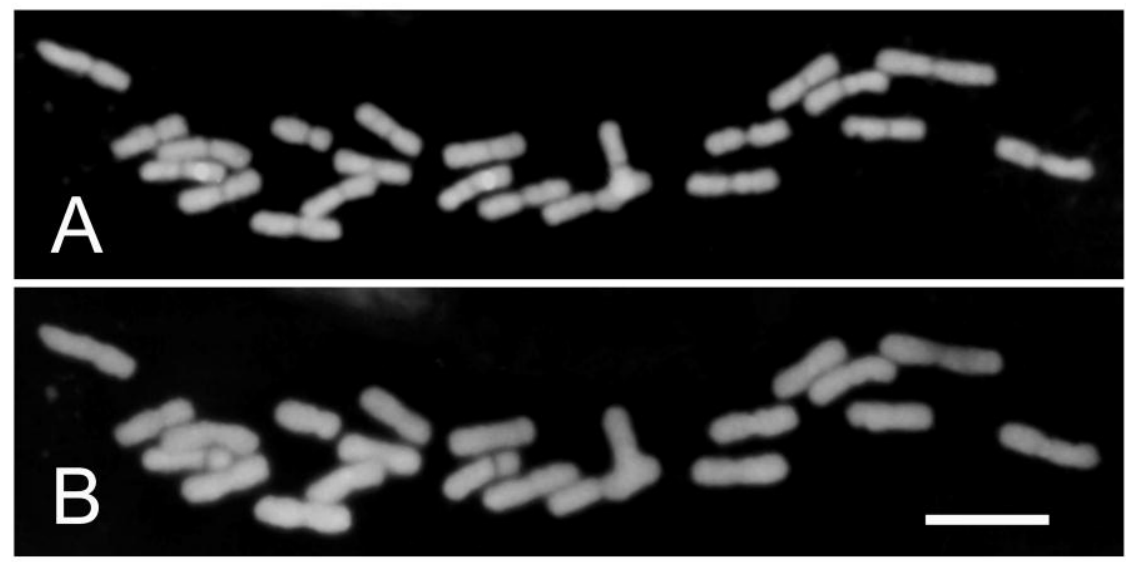

Fig. 6. Fluorescent banded chromosomes in Platycladus orientalis. A was stained with CMA and B was stained with DAPI. Bar $=10 \mu \mathrm{m}$.

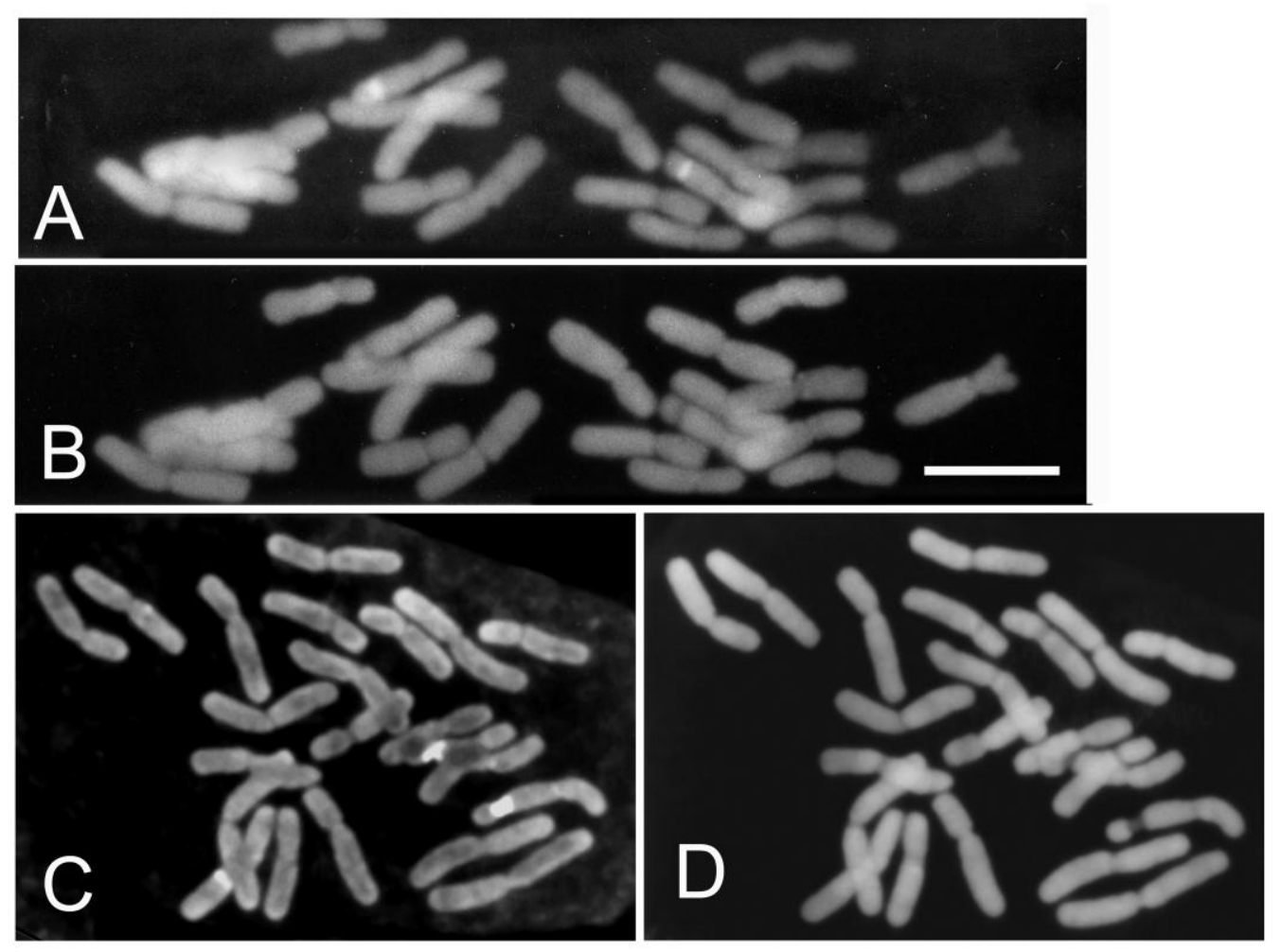

Fig. 7. Fluorescent banded chromosomes in Thuja plicata (A, B) and T. standishii $\quad$ (C, D). A and C were stained with CMA. B and D were stained with DAPI. Bar $=10 \mu \mathrm{m}$.

previous work (Kuroki 1969) and suggests presence of another secondary constriction on different chromosome in some plants or population.

Thuja plicata (Fig. 7A, B) and T. standishii (Fig. 7C, D) had similar karyotypes with each other. The karyotypes were composed of 11 pairs of meta- or submetacentric chromosomes with gradual change in length among chromosome pairs. These karyotypes were similar to those of the previous reports (Kuroki 1969). CMA-bands appeared on a pair of chromosomes at distally interstitial regions (Fig. 7A, C). The CMA-banded regions showed DAPI-negative.

The observation on karyotypes by the fluorescent banding technique was performed just in small part of species and genera in Cupressaceae sensu stricto. More than the other species and genera should be investigated on karyotype by fluorescent banding and FISH in order to clarify phylogenetic relationships among the genera or species studied in the Cupressaceae sensu stricto in the point of view of the chromosome or genome. 


\section{LiTERATURE CiTED}

Ahuja, M. R. 2005. Polyploidy in gymnosperms: Revised. Silvae Genet. 54: 59-69.

Camara, A. and Jesus, A. 1946. Um estudo citologico de Cupressus lucitanica Miller. Agr. Lusitania 8: 95-122.

De Azkue, A. 1982. Los cromosomas de Pilgerdendron uviferum (Don) Fl. Darwiniana 24: 19-22.

Farjon, A. 2001. World Checklist and Bibliography of Conifers 2nd Ed. Roy. Bot. Gard., Kew.

Farjon, A. 2005. A monograph of the Cupressaceae and Sciadopitys. Roy. Bot. Gard., Kew.

Gadek, P. A., Alpers, D. L., Heslewood, M. M. and Quinn, C. J. 2000. Relationships within Cupressaceae sensu lato: Combined morphological and molecular approach. Am. Journ. Bot. 87: 1044-1057.

Hair, J. B. 1968. The chromosomes of the Cupressaceae. I. Tetraclineae and Actinostrobeae (Callitoideae). N. Z. Journ. Bot. 6: 277-284.

Hizume, M. 1989. Karyomorphological studies in twelve species in the Taxodiaceae with special references to cytotaxonomical position of Sciadopitys verticillata. Mem. Fac. Educ. Ehime Univ. Ser. III, 9:7-32.

Hizume, M. 1996. Localization of 18S ribosomal RNA genes in the meiotic chromosomes of Cunninghamia lanceolata and Cryptomeria japonica, Taxodiaceae. Chromosome Inf. Serv. 60: 22-24.

Hizume, M. 2014. Chromosome analysis in Cupressus sempervirens L., Cupressaceae s. s. Chrom. Bot. 9:125-128.

Hizume, M., Abe, K. K. and Tanaka, A. 1988. Fluorescent chromosome bandings in Taxodiaceae. Kromosomo II-50: 1609-1627.

Hizume, M., Shibata, F. and Kondo, T. 1998. Fluorescence in situ hybridization of ribosomal RNA gene in Cryptomeria japonica, Taxodiaceae. Chromosome Sci. 2: 99-102.

Hizume, M., Tominaga, K. and Tanaka, A. 1988c. Fluorescent chromosome banding in Larix leptolepis (Pinaceae). Bot. Mag. Tokyo 101: 333-336.

Hunziker, J. H. 1961. Estudios cromosomicos en Cupressus y Libocedrus (Cupressaceae). Rev. Invest. Agr. 15:169-185.

Kondo, T. and Hizume, M. 1982. Banding for the chromosomes of Cryptomeria japonica D. Don. Journ. Jpn. For. Soc. 64: 356-358.

Kuroki, Y. 1969. Karyotype studies on important conifers. Bull. Miyazaki Univ. Forests 5: 1-103. In Japanese.

Kusumi, J., Tsumura, Y., Yoshimaru, H. and Tachida, H. 2000. Phylogenetic relationships in Taxodiaceae and Cupressaceae based on matK, chIL, trnL-trnL-trnF IGS region and trnL intron sequences. Am. Journ. Bot. 87: 1480-1488.

$\mathrm{Li}, \mathrm{L}$. and $\mathrm{Fu}, \mathrm{Y}$. 1996. Studies on the karyotypes and the cytogeography of Cupressus (Cupressaceae). Acta Phytotax. Sinica 34: 117-123. In Chinese.

Li, L. and Hsu, P. 1984. Karyotype analysis in Platycladus orientalis and Fokienia hodginsii. Acta Bot. Yunnanica 6:447-451. In Chinese.

Li. L., Cong, B., Liu, G., Liu, Y-Q. and Weng, R-F. 1994. Karyotype analysis of 3 species of Callitris (Cupressaceae) in Australia and its phylogenetic significance. Acta Bot. Yunnanica 16:349-353. In Chinese.

Li, L., Cen, Y-Q., Xu, P. and Wang, H-J. 1996a. Studies on the karyotypes of Chamaecyparis and the cytotaxonomy of Cupressoisdeae. Acta Bot. Yunnanica 18:72-76. In Chinese.

Li, L., Liu, Y-Q., Wang, Y-Q. and Liu, G. 1996b. Studies on the karyotypes of three species and the cytotaxonomy of Thjoideae (Cupressaceae). Acta Bot. Yunnanica 18:439-444. In Chinese.

Little, D. P. 2006. Evolution and Circumscription of the True Cypresses (Cupressaceae: Cupressus). Syst. Bot. 31: 461480

Maeda, T. and Miyajima, H. 1977. Cytological study on plus tree of Chamaecyparis obtuse D. et Z. -Cytological observation on Fuji 2 presumed to be a hybrid between $C$. obtuse and $C$. pisifera. J. Jpn. For. Soc. 59:213-220. In Japanese.

Mehra, P. N. and Khoshoo, T. N. 1956 Cytology of conifers I. J. Genet. 54:163-180.

Nagano, K., Matoba, H., Yonemura, K., Matsuda, Y., Murata, T. and Hoshi, Y. 2007. Karyotype analysis of three Junipers species using fluorescence in situ hybridization (FISH) with two ribosomal RNA genes. Cytologia 72: 37-42.

Nagano, K., Umeda, K. and Toda, Y. 2000. Karyomorphological study of Juniperus. In ed. Guttenberger, H. et al., Cytogenetics Studies of Forest Trees and Shrubs. pp. 143-159. Inst Plant Physiol, Univ. Graz, Graz.

Nakamura, M. and Fukui, K. 1997. A chromosome-oriented approach to genome analysis in a woosy plant-Sequoiadendron giganteum (Lindl.) Buchholz. In Eds. Borzan Z. and Schlarbaum, S. E., Cytogenetics Studies of the Forest Trees and Shrub Species, pp. 89-102. Zagreb.

Ohguro, T. and Okamura, M. 1987. Morphological and cytological studies on hybridization among Chamaecyparis obtuse Sieb. et Zucc., C. pisifera Sieb. et Zucc. and $C$. lawsoniana Parl. Bull. For. Tree Breed. Inst. 5:59-87. In Japanese.

Sasaki, Y. 1976. Karyotype studies on some conifers. Bull. Ooita Pref. For. Expt. Sta. 7:1-103. In Japanese.

Schalbaum, S. and Tsuchiya, T. 1975. Chromosomes of incense cedar. J. Hered. 66:41-42.

Thomas, G. E. and Goggans, J. F. 1972. A katyotypic studies of cypresses indigenous to Southern United States. Agr. Exp. Sta. Auburn Univ. Cir. 201:3-24.

Toda, Y. 1996. Karyomorphological studies of the Taxodiaceae. For. Genet. 3:141-146.

Vallès, J., Garnatje, T., Robin , O. and Siljak-Yakovlev, S. 2015. Molecular cytogenetic studies in western Mediterranean Juniperus (Cupressaceae): a constant model of GC-rich chromosomal regions and rDNA loci with evidences for paleopolyploidy. Tree Genet. Genomes 11:1-8.

Yang, Z., Ran, J. and Wang, X. 2012. Three genome-based phylogeny of Cupressaceae s.l.: Further evidence for the evolution of gymnosperms and Southern Hemisphere biogeography. Mol. Phylogenet. Evol. 64:452-470. 